\title{
Self-Reported Prevalence Musculoskeletal Pain/Discomfort of Farmers involved in Potato Cultivation Activities: An Ergonomic Study
}

\author{
Katayani $^{1 *}$, Aradhana Kushwaha ${ }^{1}$, Dipika Schan ${ }^{1}$ and Rekha Dayal ${ }^{2}$ \\ ${ }^{1}$ Department of FRM, ${ }^{2}$ MAB College of Home Science, C.S.A.U.A. \& T., Kanpur, India \\ *Corresponding author
}

\section{Keywords \\ Ergonomic, Work- Related MSD, \\ Nordic \\ Musculoskeletal \\ Questionnaire}

Article Info

Accepted:

18 February 2019

Available Online:

10 March 2019

\section{A B S T R A C T}

A part from cereal production (rice, wheat, etc.) agricultural labourers is engaged in vegetable Cultivation in, Kannauj, India. Potato cultivation is one of the important vegetable cultivation in India. The potato cultivation tasks are repetitive in nature and those are carried out mainly by manual efforts. Most of the tasks of potato cultivation are monotonous, strenuous, physiologically demanding as well as time-consuming. Present study entitled "Musculoskeletal Discomfort of Farmers involved in Potato Cultivation Activities: An Ergonomic Study" Potato cultivation is a physically arduous occupation that places potato growers in potential risk of musculoskeletal disorders, which impose a greater impact on their health. To assess musculoskeletal discomfort among potato growers, NORDIC (1987) standardized questionnaire designed for the analysis of musculoskeletal discomfort of complete body parts with special reference to low back, shoulders and neck. Multistage purposive random sampling technique was followed to select the state, district, blocks and finally respondents. District Kannauj is purposively selected as this is one of the largest potato producer districts while two blocks namely Kannauj and Jalabad were randomly selected. Two villages from each selected block i.e. Basirapur and Mahmoadpur paith from Kannauj and, Badlepurwa and Kheda from Jalalabad, selected randomly. Forty farmers from each selected village, Total sample size 160 respondents were randomly selected for final data collection. Maximum pain/discomfort was reported in lower back. Majority respondents felt pain that sustained for more than 12 hours in different body parts i.e. neck, shoulders right and left, elbows, wrist/hands, and ankles/feet. More than sixty five per cent respondents were suffering from gastric or other abdominal issues and cataract while 50.62 percent respondents found suffering from Anemia disease. Sixty nine per cent respondents were injured as a result of home/farming accidents, whereas 54.37 percent respondents injured due to cut or hit as a part of activity like hand/foot cut with sickle or spade etc.

\section{Introduction}

India is primarily an agrarian economy as farming is one of the most important occupations in the country and agriculture sector is the prime mover of economic growth 
in Uttar Pradesh. A vast majority of the population in the state virtually relies on the agriculture for its livelihood. As high as 65 per cent of the total workforce in the state depends on the agriculture, most of whom are below poverty line. Besides this, most of the agricultural activities are carried out mainly through manual efforts. The global area under potato during 1998 was about 18 million ha with a total production of about 295 million tonnes. U.P. is the major potato growing state in India followed by West Bengal and Bihar with the production of $10455.30,7482.30$ and 1720.20 thousand tones, respectively. The highest productivity of the crop is in West Bengal followed by Gujrat. In respect to Uttar Pradesh, Kannauj district is the highest producer of potato followed by Farrukhabad and Agra with the production of 942299, 832744 and 647025 metric tonnes and area being 34595, 29793and 18156 hectares, respectively. But in average productivity (q. /ha) district Agra first having place (356.37) followed by Mathura (339.37 q/ha) and Rampur (336.49 q/ha) (Anonymous 20012002).Pain, discomfort and loss of function in the back, neck and extremities are common among working people. These ailments are commonly termed musculoskeletal disorders (MSDs). So, the WMSDs are defined as impairments of bodily structures such as muscles, joints, tendons, ligaments, nerves or the localized blood circulation system that are caused or aggravated primarily by the performance of work and by the effects of the immediate environment in which work is being carried out. Most work-related MSDs are cumulative disorders, resulting from repeated exposure to high- or low-intensity loads over a long period of time. However, MSDs can also be acute traumas, such as fractures, that occur during an accident. The symptoms may vary from discomfort and pain to decreased body function and invalidity. Although it is not clear to what extent MSDs are caused by work, their impact on working life is huge. MSDs can interfere with activities at work, and can result in absence from work and chronic occupational disability. The consequences may include decreased productivity, a financial burden for the worker, for society and social disadvantages for the work.

\section{Materials and Methods}

The study was conducted in Kannauj district of Uttar Pradesh during the year 2015. The pre-coded interview schedule was constructed in order to elicit information needed to obtain the objectives of the study. Multistage purposive random sampling technique was followed to select the state, district, blocks and finally respondents. District Kannauj is purposively selected as this is one of the largest potato producer districts while two blocks namely Kannauj and Jalabad were randomly selected. Two villages from each selected block i.e. Basirapur and Mahmoadpur paith from Kannauj and, Badlepurwa and Kheda from Jalalabad, selected randomly. Forty farmers from each selected village, Total sample size 160 respondents were randomly selected for final data collection.

\section{Results and Discussion}

(66.25\%) respondents accepted that they had pain in neck during last year, which lasted for at least 12 hours while more than ninety per cent respondents agreed that they had pain in neck in last month that remain for at least 12 hours More than seventy per cent respondents were found having pain in right shoulder that lasted for at least 12 hour in previous year, whereas about eighty eight per cent respondents accepted pain in right shoulder that lasted for at least 12 hours in previous month. About ninety one per cent respondents suffered pain in left shoulder that lasted for at least 12 hours in previous week. A little less than eighty five per cent respondents accepted 
feeling of pain in right elbow that continued for at least 12 hours in last year while about eighty one per cent respondents felt pain in right elbow that sustained for at least 12 hours in previous month. Seventy five per cent respondents accepted pain in both elbow that lasted for at least 12 hours in last 12 months while 62.50 percent and 87.50 percent respondents complaint pain in both the elbows which lasted for at least 12 hours in previous months and last seven days respectively (Table 1).

Table.1 Distributions of Respondents on the Basis of Self-Reported Prevalence of

Musculoskeletal Pain/Discomfort

$\mathrm{N}=160$

\begin{tabular}{|c|c|c|c|c|c|c|c|}
\hline \multirow[t]{2}{*}{$\begin{array}{l}\text { S. } \\
\text { No } \\
\text { - }\end{array}$} & \multirow[t]{2}{*}{$\begin{array}{l}\text { Body } \\
\text { part }\end{array}$} & \multicolumn{2}{|c|}{$\begin{array}{l}\text { Pain/discomfort during last } 12 \\
\text { month lasting for at least } 12 \\
\text { hours }\end{array}$} & \multicolumn{2}{|c|}{$\begin{array}{l}\text { Pain/discomfort during } \\
\text { last month lasting for at } \\
\text { last12 hours }\end{array}$} & \multicolumn{2}{|c|}{$\begin{array}{l}\text { Pain/discomfort during last } \\
\text { Seven days lasting for at least } 12 \\
\text { hours }\end{array}$} \\
\hline & & NO & YES & NO & YES & NO & YES \\
\hline 1 & Neck & $\begin{array}{c}54 \\
(33.75)\end{array}$ & $106(66.25)$ & $12(07.5)$ & $148(92.5)$ & $107(66.87)$ & $53(33.12)$ \\
\hline \multirow[t]{4}{*}{2} & \multicolumn{7}{|l|}{ Shoulder } \\
\hline & Right & $\begin{array}{c}45 \\
(28.12)\end{array}$ & $115(71.87)$ & $20(12.50)$ & $140(87.5)$ & $82(51.25)$ & $78(48.75)$ \\
\hline & Left & $\begin{array}{c}145 \\
(90.62)\end{array}$ & $15(09.37)$ & $\begin{array}{c}105 \\
(65.62)\end{array}$ & $55(34.37)$ & $81(50.62)$ & $145(90.62)$ \\
\hline & Both & $\begin{array}{c}141 \\
(88.12)\end{array}$ & $19(11.87)$ & $\begin{array}{c}106 \\
(66.25)\end{array}$ & $54.00(33.75)$ & $10(06.25)$ & $150.00(93.75)$ \\
\hline \multirow[t]{4}{*}{3} & \multicolumn{7}{|l|}{ Elbow } \\
\hline & Right & $\begin{array}{c}25 \\
(15.62)\end{array}$ & $135(84.37)$ & $\begin{array}{c}129 \\
(80.62)\end{array}$ & $31(19.37)$ & $135(84.37)$ & $25(15.62)$ \\
\hline & Left & $\begin{array}{c}11 \\
(06.87)\end{array}$ & $149(93.12)$ & $31(19.37)$ & $129(80.62)$ & $95(59.37)$ & $65(40.62)$ \\
\hline & Both & $\begin{array}{c}40 \\
(25.00)\end{array}$ & $120(75.00)$ & $60(37.50)$ & $100(62.5)$ & $20(12.50)$ & $140(87.5)$ \\
\hline \multirow[t]{4}{*}{4} & \multicolumn{7}{|c|}{ Wrist/hands } \\
\hline & Right & $\begin{array}{c}11 \\
(06.87)\end{array}$ & $149(93.12)$ & $\begin{array}{c}102 \\
(63.75)\end{array}$ & $58(36.25)$ & $102(63.75)$ & $37(23.12)$ \\
\hline & Left & $\begin{array}{c}58 \\
(37.25)\end{array}$ & $102(63.75)$ & $37(23.12)$ & $123(76.87)$ & $11(06.87)$ & $149(93.2)$ \\
\hline & Both & $\begin{array}{c}17 \\
(10.62)\end{array}$ & $143(89.37)$ & $40(25.00)$ & $120(75.00)$ & $64(40.00)$ & $96(60.00)$ \\
\hline 5 & $\begin{array}{l}\text { Upper } \\
\text { back }\end{array}$ & $\begin{array}{c}130 \\
(81.25)\end{array}$ & $30(18.75)$ & $50(31.25)$ & $110(68.75)$ & $110(68.75)$ & $50(31.25)$ \\
\hline 6 & $\begin{array}{l}\text { Lower } \\
\text { back }\end{array}$ & $\begin{array}{c}120 \\
(75.00)\end{array}$ & $40(25.00)$ & $85(53.12)$ & 75 (46.87) & $107(66.87)$ & $53(33.12)$ \\
\hline 7 & $\begin{array}{l}\text { Hips/thig } \\
\text { hs }\end{array}$ & $\begin{array}{c}135 \\
(84.37)\end{array}$ & $25(15.62)$ & $\begin{array}{c}104 \\
(65.00)\end{array}$ & $56(35.00)$ & 79 (49.37) & $81(52.50)$ \\
\hline 8 & Knees & $\begin{array}{c}130 \\
(81.25)\end{array}$ & $30(18.75)$ & $132(82.5)$ & $28(17.50)$ & $91(56.87)$ & $69(43.12)$ \\
\hline 9 & $\begin{array}{l}\text { Ankles/ } \\
\text { feet }\end{array}$ & $\begin{array}{c}40 \\
(25.00)\end{array}$ & $120(75.00)$ & $50(31.25)$ & $110(68.75)$ & 79 (49.37) & $81(50.62)$ \\
\hline
\end{tabular}

Above ninety per cent respondents reported pain in right wrist that sustained for at least 12 hours during last 12 months. A little less than ninety per cent respondents accepted the feeling of pain in both the writs/hands which lasted for at least 12 hours in last 12 months 
and seventy five per cent respondents were suffering pain in both the hand which continued at least for 12 hours in last month. Sixty per cent respondents were having pain in both wrists/hands during last seven days which lasts for at least 12 hours, whereas, little less than seventy per cent respondents having pain in upper back which sustained for 12 hours in last month. More than forty five per cent respondents reported pain in lower back that sustained for at least 12 hours in last month. Majority $(84.37 \%)$ respondents did not complain any pain in hips/thighs that last for at least 12 hours in during last 12 month and More than eighty one and 82.50 per cent respondents were not having pain in knees which continued for at least 12 hours. Majority $(75.00 \%, 68.75 \%)$ and $50.62 \%)$ of respondents were having pain which sustained for more than 12 hours in last 12 month, last month and last seven days respectively. Musculoskeletal discomfort felt at Upper back and elbows were also negatively correlated with age of the respondents. Positive significant relationship was observed between age of the respondents and musculoskeletal pain/ discomfort reported in neck, shoulder, low back and wrist/hand.

In conclusion, the potato cultivation tasks are repetitive in nature and those are carried out mainly by manual efforts. Most of the tasks of potato cultivation are monotonous, strenuous, physiologically demanding as well as timeconsuming. The prevalence of MSDs was very high among the workers and the most affected areas were back and upper extremity. Postural analysis indicated that the subjects had to adopt different stressful postures during performing different potato cultivation jobs. During potato cultivation operations the workers were subjected to greater postural stress. Postural stress might be the reason of the occurrence of MSDs. From this study it has been recommended that workers should avoid bad work postures as far as possible during work for reducing job related health hazards.

\section{References}

Anonymous. (2001-02) All India Coordinated Research Project in Home Science: Annual Report, ICAR, New Delhi, India.

Osborne, A.; Blake, C.; McNamara, J.; Meredith, D. and Phelan, J. (2010) Musculoskeletal disorders among Irish farmers. Occup Med (Lond) 60: 598603.

Kuorinka, B.; Jonsson, A.; Kilbom, H.; Vinterberg, F. and Andersson, K. (1987) Standardized Nordic questionnaires for the analysis of musculoskeletal symptoms. Applied Ergonomics. 18(3): 233-237.

\section{How to cite this article:}

Katayani, Aradhana Kushwaha, Dipika Schan and Rekha Dayal. 2019. Self-Reported Prevalence Musculoskeletal Pain/Discomfort of Farmers involved in Potato Cultivation Activities: An Ergonomic Study. Int.J.Curr.Microbiol.App.Sci. 8(03): 2206-2209. doi: https://doi.org/10.20546/ijcmas.2019.803.264 